\title{
Recurrent chest infections, ciliary abnormalities and partial complement deficiency in a Jordanian family
}

\author{
ID STARKE, B CORRIN, PJ SELBY, ADB WEBSTER, M TURNER-WARWICK \\ From the Cardiothoracic Institute and Brompton Hospital and St Thomas's Hospital Medical School, \\ London, and the Clinical Research Centre, Harrow, Middlesex
}

\begin{abstract}
Four girls born to second cousin parents developed chronic chest infection and bronchiectasis in infancy. Three were studied in detail: they all had the same HLA haplotype, all showed random orientation of cilia or compound cilia in the respiratory tract, and all had low levels of the $\mathrm{C} 1$ and $\mathrm{C} 2$ components of the complement system. Although the cause of the respiratory disease in this family remains unclear, it is suggested that the low $\mathrm{C} 1$ levels may have contributed to the disease in two of the children while the low C2 levels were artefacts and the ciliary abnormalities were secondary to chronic chest infection.
\end{abstract}

We have recently encountered a Jordanian family in which four children born to second cousin parents suffered from recurrent chest infections and bronchiectasis. An inherited abnormality was suspected and, because primary defects in host defence often have a genetic basis, ${ }^{1-3}$ we have investigated defence mechanisms against infection as fully as possible in this family.

\section{Case histories}

\section{CASE 1}

This girl (As $\mathrm{J}$, aged 10 years) had had a productive cough and catarrh since infancy. At 8 years she had been admitted to a sanatorium with suspected, but unconfirmed, pulmonary tuberculosis. At 9 years she had undergone a left pneumonectomy. On examination she was a small, thin child with scattered crackles and wheezes over the right hemithorax. Her chest radiograph showed absence of the left lung, right middle lobe collapse and bronchial wall thickening at the right base. The maxillary sinuses were opaque and the frontal sinuses were absent.

\section{CASE 2}

This girl (Kh J, aged 9 years) had been short of

Address for reprint requests: Dr ID Starke, MRC Leukaemia Unit, Royal Postgraduate Medical School, Hammersmith Hospital, Ducane Road, London W12 0HS. breath and had had a productive cough since infancy. On examination she had finger clubbing and central cyanosis. There was dullness to percussion and widespread crackles were heard over the left hemithorax. The chest radiograph showed a con-

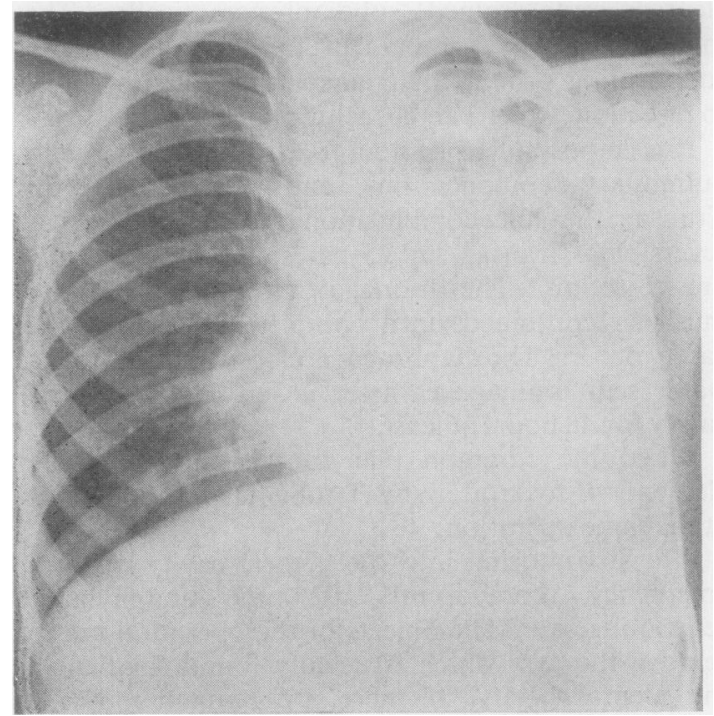

Fig 1 Chest radiograph of patient 2. There is contraction of the left lung with widespread cavity formation, together with some consolidation in the right lower zone. 
tracted left lung with multiple cavities in the upper zone (fig 1). The maxillary sinuses were opaque and the frontal sinuses were absent. In view of the severity of the disease affecting the left lung, left pneumonectomy was carried out.

A boy (Fi J) died aged 6 years and was not seen by us. He had had a productive cough throughout his life. Shortly before his death he had developed a swelling of the right jaw and hilar lymphadenopathy for which he had received radiotherapy.

\section{CASE 3}

In this girl (Ey $\mathrm{J}$, aged 5 years) a productive cough and sinusitis had been present since infancy. On examination she had finger clubbing and there were coarse crackles and wheezes over both sides of the chest. The chest film showed moderately dense shadowing involving both lower lobes, the middle lobe and the lingula, with dilated bronchi visible at both lung bases (fig 2 ). The maxillary sinuses were opaque.

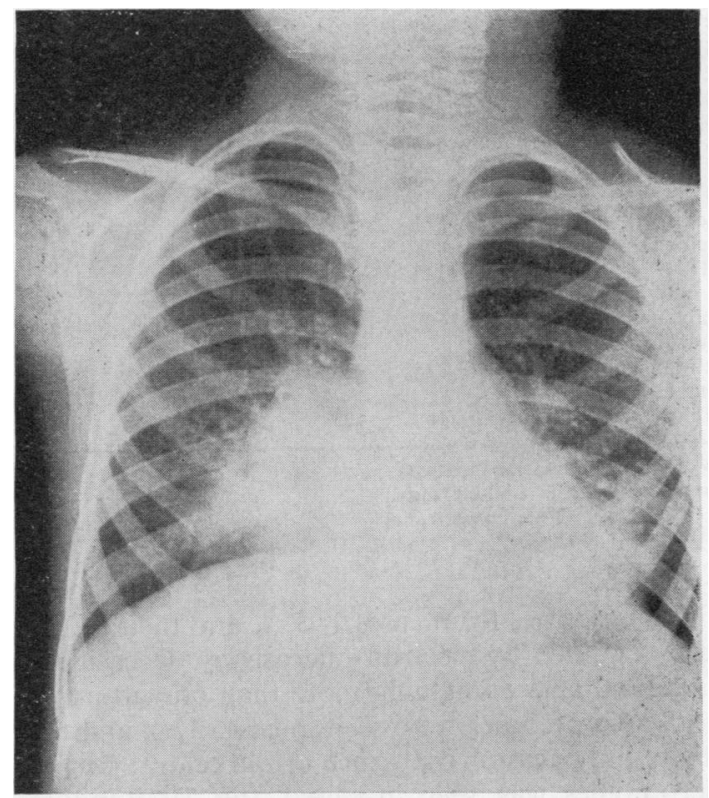

Fig 2 Chest radiograph of patient 3. There is bilateral consolidation involving both lower lobes, middle lobe, and lingula.

\section{CASE 4}

Qu J (a girl, aged 3 years) had had a productive cough and sinusitis since infancy but was less severely affected than her sisters. She had finger clubbing and there were coarse crackles and wheezes over the whole chest. The chest film showed shadowing in the middle lobe and in both lower lobes with dilated bronchi in the lower lobes. The maxillary sinuses were opaque.

Fa J, a baby girl, died aged 6 weeks and was not seen by us. She weighed 900 grams at birth and failed to thrive, but she had no evidence of chest disease and her chest film was normal.

Fy J, a boy, aged 8 months, was not seen by us. He was the twin of $\mathrm{Fa} \mathrm{J}$. He was well and had a normal chest film at 8 months of age.

The father, aged 36 years, and mother, aged 30 years, were second cousins. Both had been healthy throughout their lives and the father was normal on physical examination. The mother was not seen by us, but both parents had normal chest radiographs.

\section{Investigations}

Cases 1-4 were investigated. All were below the twenty-fifth percentile for height and below the tenth for weight. Electrocardiograms were normal. All four had an elevated ESR (38-65 $\mathrm{mm} / \mathrm{hr}$ ) and a raised leucocyte count $\left(12 \cdot 7-17 \cdot 5 \times 10^{\circ} / 1\right)$. Serum electrolytes, glucose, alkaline phosphatase, SGOT, bilirubin, and albumin were all normal. Total globulin, IgG, IgA, and IgM levels were normal or elevated. The sweat sodium concentration was normal on two to five occasions in each child and faecal fat excretion was normal in the three children in whom it was measured.

\section{MICROBIOLOGY}

Haemophilus influenzae was found in the sputum of all four children and Streptococcus pneumoniae was cultured once from the sputum of case 1. Candida albicans was cultured from case 1 and Aspergillus fumigatus from case 2 on one occasion each. Repeated cultures of sputum for Mycobacteria spp were negative.

\section{SEROLOGY}

Rheumatoid factor, antinuclear factor and autoantibodies to smooth muscle, reticulin, mitochondria, thyroid cytoplasm and gastric parietal cells were absent. Isohaemagglutinin (anti-B) titres were normal and serum precipitins to Aspergillus fumigatus and Candida albicans were not detected in any of the four cases. Serological tests for syphilis were negative. Immunisation with TAB vaccine, tetanus toxoid, and influenza vaccine produced adequate increases in specific antibody titres in all four cases.

\section{TISSUE TYPING}

Case 1,3 , and 4 were of haplotype HLA $a_{1} b_{12} / a_{1} b_{12}$ and their father was HLA $a_{1} b_{12} / a_{1} b_{5}$. All four children were of blood group A rhesus positive. 
Table 1 Lymphocyte and neutrophil studies

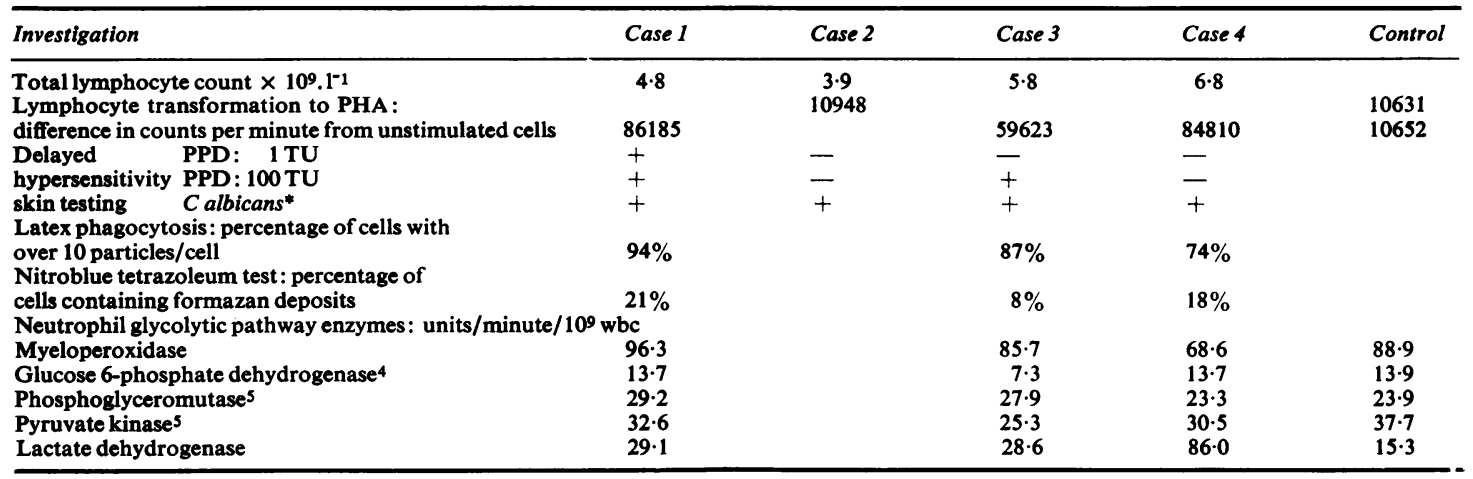

PHA $=$ phytohaemagglutinin, greatest response to 0.2 or 0.5 mitogenic units $/ \mathrm{ml}$.

* = Candida albicans, Hollister-Stier antigen.

Table 2 Further neutrophil function studies in case 1

\begin{tabular}{|c|c|c|}
\hline & Case 1 & Control \\
\hline $\begin{array}{l}1 \text { Adherence to nylon wool } \\
2 \text { Polymorph chemotaxis and migration } \\
\text { into skin window } 6 \\
3 \mathrm{CO}_{2} \text { production from yeast stimulated } \\
\text { polymorphs after two hours. } \\
\text { Counts/minute } 7 \\
\text { polymorphs alone } \\
\text { polymorphs + yeast } \\
4 \text { Quantitative NBT* reduction: } \\
\text { mmol formazan per ml blood8 } \\
5 \text { Killing of Staphylococcus aureus: } \\
\text { organisms/ml } 9 \\
\text { at start } \\
\text { after two hours }\end{array}$ & $\begin{array}{c}561 \\
1493 \\
\\
0.0083\end{array}$ & $\begin{array}{c}397 \\
1990 \\
0.0089\end{array}$ \\
\hline
\end{tabular}

*NBT = nitroblue tetrazoleum.

LYMPHOCYTE AND NEUTROPHIL STUDIES

Details of the investigations carried out and of the results obtained are given in tables 1 and 2 . The only abnormality detected was a rather reduced lymphocyte transformation to phytohaemagglutinin (PHA) in case 2. She was tested on a different occasion from the other three cases and her PHA response was similar to that of her control.

\section{COMPLEMENT STUDIES}

Sera from cases 1,3 , and 4 were studied on two occasions each. Low activities of $\mathrm{C} 1$ and $\mathrm{C} 2$ were found in comparison with normal laboratory control sera, while activities of the alternative pathway and of $\mathrm{C} 3$ and subsequent components of the complement system were normal (table 3 ).

MICROSCOPY

Sections from the pneumonectomy specimens of cases 1 and 2 showed dilated bronchi with chronic inflammatory cell infiltration and loss of epithelium. There was no evidence of cartilage deficiency or of proximal bronchial stenosis.
Table 3 Levels of activity of the components of the complement pathway in cases 1,3 , and 4 on two occasions, six months apart.

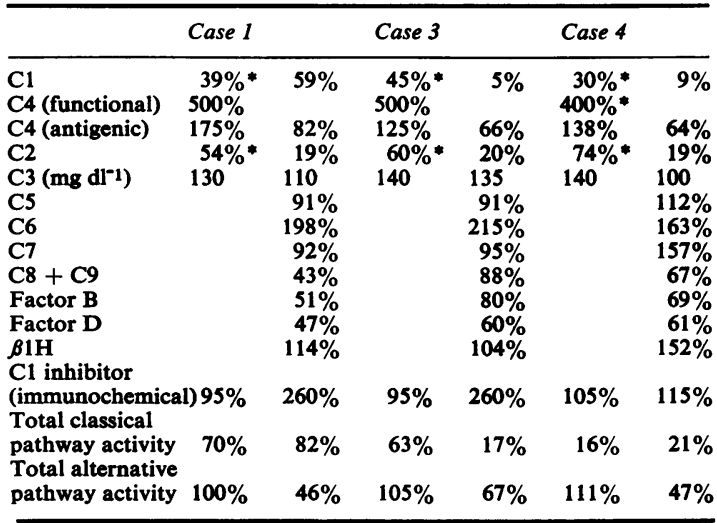

" = "Target" formation (see text).

Normal ranges: $\mathrm{C3}=60-180 \mathrm{mg} \mathrm{dl}^{-1}$, Other components $=60 \%-180 \%$ of normal human serum ${ }^{10}$

Nasal biopsies from cases $1,3,4$, and their father were examined by electron microscopy. Occasional compound cilia containing more than one group of $9+2$ microtubules were seen in cases 1,4 , and the father, and occasional absence of the central pair of microtubules was seen in case 1 (fig 3). Random orientation of the cilia was seen in cases 1,3 , and the father (figs 4,5 ). Tissue preservation did not permit adequate examination of radial spokes or, in cases 1 and 4, of dynein arms, but the latter structures were identified in case 3 and the father (fig 4, insert).

\section{Discussion}

Interest in this family centres on the combination of abnormal cilia and deficiencies in the complement system. A number of different abnormalities of 


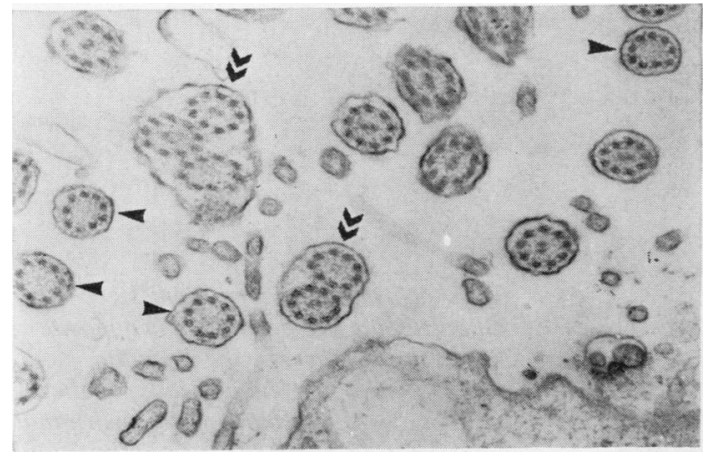

Fig 3 Nasal biopsy of patient 1. Compound cilia containing more than one group of $9+2$ microtubules are seen (double arrowheads) and some cilia lack the central pair of microtubules (single arrowheads).

Electronmicrograph original magnification $\times 39500$.

respiratory tract cilia have been reported in association with chronic chest infections or with bronchiectasis. A lack of axonemal (dynein) arms on the outer microtubular doublets of the cilia of patients with Kartagener's syndrome have been described, often in association with male infertility and with immotile spermatozoa which also lack dynein arms. ${ }^{11-13}$ The term Immotile Cilia Syndrome has been proposed to include such cases, and also incomplete forms of Kartagener's syndrome with absent ciliary dynein arms. ${ }^{1314}$ Absent radial spokes in the immotile nasal and bronchial cilia of a family with recurrent respiratory infections has been reported recently. ${ }^{15}$

In the family that we have studied dynein arms and radial spokes were present in the cilia of at least some members, but all showed other ciliary abnormalities including random orientation, compound cilia and absence of central microtubules, alterations which have been reported in patients with bronchial carcinoma and with asthma and in animals exposed to carcinogens or to $50 \%$ oxygen. ${ }^{16-20}$ Thus the abnormal cilia in the children may have been coincidental or secondary to their recurrent infections. The healthy father of our patients also displayed random orientation of cilia and compound cilia, and it is therefore likely that some additional defect existed in the children to account for their chronic respiratory infection. The only abnormalities found apart from those affecting the cilia were in the complement system.

The levels of $\mathrm{C} 2$ detected were compatible with heterozygous $\mathrm{C} 2$ deficiency on only one of the two estimations in each child. ${ }^{21}$ The usual association of C2 deficiency is with connective tissue disorders although not all heterozygous $\mathrm{C} 2$ deficient subjects have an associated disease state. ${ }^{2122}$ Reduced C2 levels have been described in some patients with recurrent bacterial upper respiratory tract infections. ${ }^{23}$ Heterozygosity for $\mathrm{C} 2$ deficiency might have occurred in all three children together with their common HLA haplotype since the $\mathrm{C} 2$ gene locus and HLA are closely linked. ${ }^{24}$ However, without known homozygous $\mathrm{C} 2$ deficiency in a family member the so-called "heterozygous C2 deficiency state" cannot be diagnosed with certainty in the presence of other abnormalities in the complement system and in the absence of HLA haplotypes $a_{10}$ or $b_{18 .}{ }^{22}$

Consumption of $\mathrm{C} 2$ as a result of active inflammatory or immune complex disease is unlikely since levels of $\mathrm{C} 2$ are relatively unaffected in comparison to levels of $\mathrm{C} 4$ or $\mathrm{C3}^{22}$ which were normal or elevated in our patients. It is therefore likely that the low C2 levels were an artefact, possibly the result of storage.

The levels of $\mathrm{Cl}$ detected were compatible with heterozygous $\mathrm{Cl}$ deficiency on both measurements in cases 3 and $4 .{ }^{24}$ However, without parental data it is impossible to be certain whether the reduced $\mathrm{Cl}$ activity was primary in these two children or whether it was secondary to their recurrent infections. The presence of "targets" on the $\mathrm{C} 1, \mathrm{C} 4$, and $\mathrm{C} 2$ plates

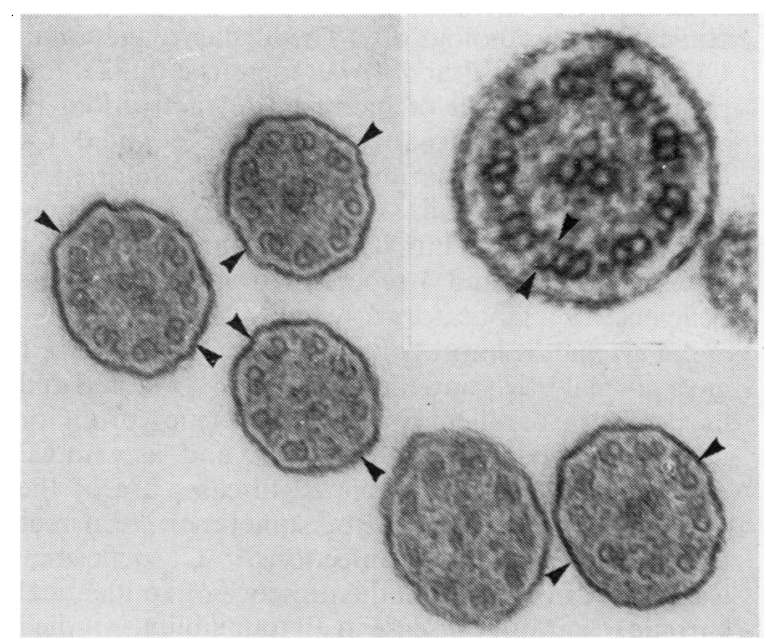

Fig 4 Nasal biopsies of the father and patient 3 (inset). The father's cilia show random orientation, as shown by the alignment of the central pair of microtubules indicated by arrowheads. Dynein arms, indicated by arrowheads in the inset, are present in patient 3.

Electronmicrographs original magnifications $\times 134000$ and (inset) $\times 192000$. 


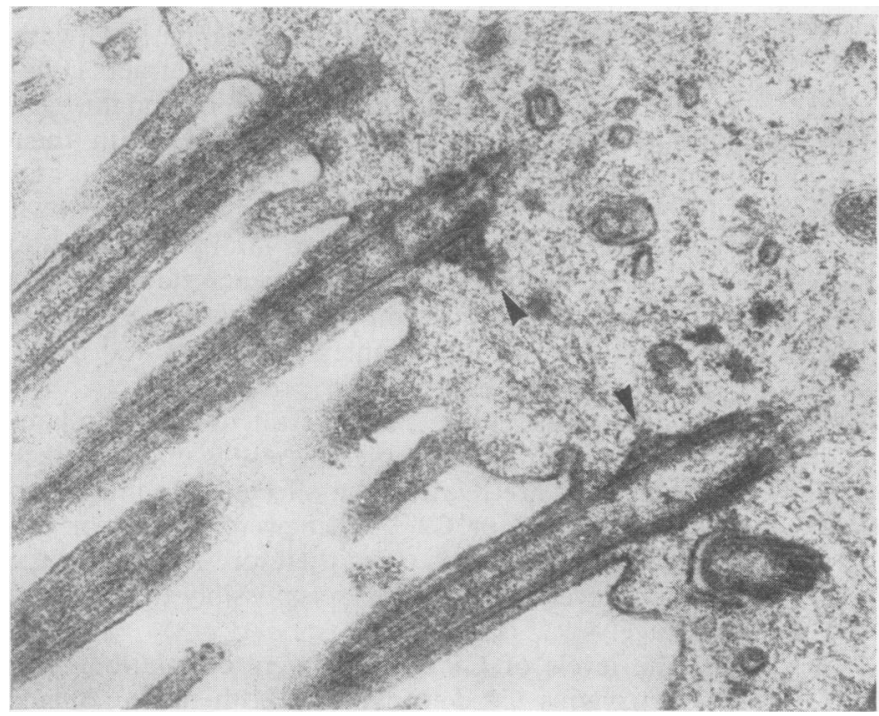

Fig 5 Nasal biopsy of patient 3. Adjacent cilia are orientated in opposite directions as shown by the direction of the lateral spurs (arrowheads) on the basal bodies. Electronmicrograph original magnification 50000 .

suggests either that activated $\mathrm{Cl}$ was present in the test serum or that some form of competitive inhibition was taking place. ${ }^{10}$ That $\mathrm{Cl}$ activation could be responsible is suggested by the finding that "target" formation only occurred on the first estimation when the children had active infection clinically.

At the time of the second estimation "targets" were absent and all the children had improved clinically and radiologically. The further reduction in $\mathrm{Cl}$ levels in cases 3 and 4 was therefore unlikely to have been the result of increased $\mathrm{Cl}$ activation. In addition the presence of normal or elevated $\mathrm{C} 4$ levels on both estimations, in all the children, is against $\mathrm{Cl}$ activation since activated $\mathrm{Cl}$ rapidly consumes $\mathrm{C}^{2} .^{2526}$ Thus it is likely that the low $\mathrm{Cl}$ levels in cases 3 and 4 represented either a genuine deficiency or a laboratory artefact.

An artefact is improbable since serum from case 1 gave normal levels and the three sera were stored and processed in parallel. However, deficiency of $\mathrm{Cl}$ or its subcomponents is extremely rare and, as with $\mathrm{C} 2$ deficiency, the usual associated diseases are of the immune complex type with, sometimes, recurrent upper respiratory tract infections. ${ }^{21} \mathrm{Cl}$ deficiency was absent in case 1 and the presence of an identical chronic respiratory disease in all four siblings studied suggests that the low $C 1$ levels in cases 3 and 4, even if genuine, were not directly responsible.

We would like to thank Professor P Lachmann, Laboratory of Molecular Biology, Cambridge University, Dr JA Sachs, Tissue Immunology Unit, The London Hospital Medical College, Mrs V Pozo, Senior Biochemist, University College Hospital, and
Mr J Fentem and Mr A Das, electron microscope technicians, St Thomas's Hospital Medical School, London for their help with the investigations in this family.

\section{References}

1 Williams H, Campbell P. Generalised bronchiectasis associated with deficiency of cartilage in the bronchial tree. Arch Dis Child 1960;35:182-91.

${ }^{2}$ Suhs RH, Dowling HF, Jackson GG. Hypogammaglobulinemia with chronic bronchitis or bronchiectasis. Arch Intern Med 1965;116:29-38.

${ }^{3}$ Ballow M, Shira JE, Harden L, Yang SY, Day NK. Complete absence of the third component of complement in man. J Clin Invest 1975;56:703-10.

${ }_{4}$ Motulsky AG, Yoshida A. In: Yunis JJ, ed. Biochemical methods in red cell genetics. New York: Academic Press, 1969:74.

5 Beutler E. Red cell metabolism. New York: Grune and Stratton, $1971: 51-2,56-7$.

6 Segal AW, Loewi G. Neutrophil dysfunction in Crohn's disease. Lancet 1976;2:219-21.

7 Baehner RL, Nathan DG. Leukocyte oxidase: defective activity in chronic granulomatous disease. Science $1967 ; 155: 835-6$.

${ }^{8}$ Segal AW, Peters TJ. The nylon column dye test: a possible screening test of phagocyte function. Clin Sci Mol Med 1975;49:591-6.

${ }^{9}$ Quie PG, White JG, Holmes B, Good RA. In vitro bactericidal capacity of human polymorphonuclear leukocytes: diminished activity in chronic granulomatous disease of childhood. J Clin Invest 1967;46:668-79.

${ }^{10}$ Lachmann PJ, Hobart MJ. Complement technology. In: Weir DM, ed. Handbook of experimental immunology. Third edition. Oxford: Blackwell Scientific Publications, 1978:5A 1-23.

11 Pedersen H, Rebbe H. Absence of arms in the axoneme of immobile human spermatozoa. Biol Reprod 1975;12: 541-4.

12 Pedersen $H$ Mygind $N$. Absence of axonemal arms in 
nasal mucosa cilia in Kartagener's syndrome. Nature 1976;262:494-5.

13 Eliasson R, Mossberg B, Camner P, Afzelius BA. The Immotile-Cilia syndrome: a congenital ciliary abnormality as an etiological factor in chronic airway infections and male sterility. $N$ Engl J Med 1977;297:1-6.

14 Afzelius BA. Kartagener's syndrome and abnormal cilia. N Engl J Med 1977;297:1012.

15 Sturgess JM, Chao J, Wong J, Aspin N, Turner JAP. Cilia with defective radial spokes: a cause of human respiratory disease. $N$ Engl J Med 1979;300:53-6.

16 Ailsby RL, Ghadially KN. Atypical cilia in human bronchial mucosa. J Pathol 1973;109:75-8.

17 Torikata C, Takeuchi H, Yamaguchi H, Kageyama K. Abnormal cilia in the bronchial mucosa. Case reports of non-smoking women with bronchogenic carcinomas and an experimental model in guinea-pigs. Virchows Arch (Pathol Anat) 1976;371:121-9.

18 McDowell E, Barrett LA, Harris CC, Trump BF. Abnormal cilia in human bronchial epithelium. Arch Pathol Lab Med 1976;100:429-36.

19 Cutz E, Levison H, Cooper DM. Ultrastructure of airways in children with asthma. Histopathology 1978;2: 407-21.
20 Harris CC, Kaufmann DG, Jackson F, Smith JM, Dedick $P$, Saffiotti U. Atypical cilia in the tracheobronchial epithelium of the hamster during respiratory carcinogenesis. J Pathol 1974; 114:17-19.

21 Agnello V. Complement deficiency states. Medicine (Baltimore) 1978;57:1-23.

22 Glass D, Raum D, Gibson D, Stillman JS, Schur PH. Inherited deficiency of the second component of complement: rheumatic disease associations. $J$ Clin Invest 1976;58:853-61.

${ }^{23}$ Repine JE, Clawson CC, Friend PS. Influence of a deficiency of the second component of complement on the bactericidal activity of neutrophils in vitro. J Clin Invest 1977;59:802-9.

24 Jersild C, Rubinstein P, Day NK. The HLA system and inherited deficiencies of the complement system. Transplant Rev 1976;32:43-71.

25 Alper CA, Rosen FS. The role of complement in vivo as revealed by genetic defects. In: Brent $\mathrm{L}$, Holborow J, eds. Progress in Immunology II. New York: Academic Press, 1974:201-8.

26 Johnston RB, Stroud RM. Complement and host defence against infection. J Pediatr 1977;90:169-79.

Cardiac Surgery Update in Jerusalem will be held in Jerusalem, Israel from 31 May to 2 June 1982. Further information may be obtained from Professor Joseph B Borman, PO Box 983, Jerusalem 91009, Israel. 